\title{
Ryggmargsskade og tarmfunksjon
}

\author{
Sammendrag \\ Bakgrunn. Ryggmargsskade gir ofte \\ varige forstyrrelser i mage-tarm-funk- \\ sjon, noe som forsterker funksjons- \\ hemningen. \\ Kunnskapsgrunnlag. Artikkelen er \\ basert på et litteratursøk i PubMed og \\ på egne kliniske erfaringer på tertiært \\ nivå i spesialisthelsetjenesten.
}

Resultater. Nevrogen gastrointestinal dysfunksjon er en vanlig og ofte varig følgetilstand etter skade på ryggmargen. Obstipasjon og fekal inkontinens medfører ofte tid- og ressurskrevende behandlingstiltak. Årsaksbehandling for tilstanden er ennå ikke mulig. Nye behandlingsmetoder med retrograd og antegrad irrigasjon av rektocolon, transanalt eller via appendikostomi, gir $ø k t$ grad av selvhjulpenhet og raskere tømmingsprosedyrer sammenliknet med konservative behandlingsmetoder. Det er nylig etablert internasjonal konsensus med standardiserte datasett for evaluering av funksjonstapet.

Fortolkning. Nevrogen gastrointestinal dysfunksjon etter ryggmargsskade bør utredes og behandles i rehabiliteringsavdeling på tertiært nivå. Behandlingen må systematisk utprøves og jevnlig evalueres i et samarbeid mellom pasient og hjelpeapparat. Det må tas hensyn til individuelle og personlige forutsetninger. Den internasjonale konsensusen gir nye og større muligheter for multisentersamarbeid om kvalitetssikring og forskning.

\section{Erik Sigurdsen}

erik.sigurdsen@stolav.no

Avdeling for ryggmargsskader

Klinikk for fysikalsk medisin og rehabilitering

St. Olavs hospital

\section{Tom Tørhaug}

Avdeling for ryggmargsskader

Klinikk for fysikalsk medisin og rehabilitering

St. Olavs hospital

og

Institutt for nevromedisin

Norges teknisk-naturvitenskapelige universitet

Ryggmargsskade medfører vanligvis raskt innsettende sensomotoriske funksjonstap med varierende grad av bevegelseshemning. Umiddelbart etter skaden vil funksjonsforstyrrelser med autonom reguleringssvakhet og muskulær atoni med bortfall av reflekser, blære- og tarmparese, hemodynamisk labilitet og ventilasjonssvikt kunne prege tilstanden. Alle disse funksjonsforstyrrelsene gir diagnostiske og behandlingsmessige utfordringer. Alvorlighetsgrad og varighet av den initiale «sjokkfasen» vil avhenge av ryggmargsskadens anatomiske nivå og omfang. Spesielt vil omfattende skader i nakkenivå kunne forlenge denne fasen. Det nevrologiske og autonome funksjonstapet bør klassifiseres etter The International standards for neurological classification of spinal cord injuries (1-3). Denne klassifikasjonen dokumenterer funksjonstapet og kan være en prognostisk markør. Det umiddelbare tapet av tarm- og urinblærefunksjon vil kunne vedvare langt ut over den akutte fasen. Tapet er ofte livslangt og medfører risiko for ytterligere komplikasjoner.

\section{Kunnskapsgrunnlag}

Grunnlaget for artikkelen er et litteratursøk i PubMed. Utvalget av artikler er skjønnsmessig gjort av forfatterne basert på mangeårig klinisk erfaring ved rehabiliteringsavdeling på tertiært nivå for pasienter med ryggmargsskader.

\section{Resultater}

Epidemiologi

Insidensen av traumatisk ryggmargsskade er svært varierende angitt: $8-52,2$ per million innbyggere per år $(4,5)$. Ved Avdeling for ryggmargsskader ved St. Olavs hospital, som dekker Helse Nord og Helse Midt-Norge med totalt ca. 1,1 millioner innbyggere, er det de siste ti år registrert om lag 30 årlige tilfeller av ryggmargsskader (upubliserte data fra egen avdeling). Litt over halvparten av disse er traumatisk betinget, mens de resterende er ikke-traumatiske. I en nyere norsk studie fant Hagen og medarbeidere en samlet prevalens på 36,5 per 100000 blant innbyggerne i fylkene Sogn og Fjordane og Hordaland (6). Gjennomsnittsalder var 42,9 år, og mann: kvinne-ratioen var 4,7:1 (6). Gjennomsnittlig debutalder ved traumatisk ryggmargsskade er forholdsvis lav, omtrent 32 år i USA og 40 år i Europa (5).

Ryggmargsskaderelatert reguleringssvakhet av tarmens funksjon har negativ innflytelse på sykelighet, dødelighet, psykososial funksjon og livskvalitet (7). Systematisk kunnskap om både kolorektal dysfunksjon og bekkenbunnsdysfunksjon har økt betydelig de siste 15 år (8). Obstipasjon og defekasjonsforstyrrelser er de mest vanlige problemene og foreligger hos ca. $80 \%$ av dem med ryggmargsskader (9). Omtrent $40 \%$ av ryggmargsskadepopulasjonen angir at kolorektal dysfunksjon begrenser sosiale aktiviteter og livskvaliteten (9). Andre studier viser økt tidsbruk, økt tømmingstrang (10), kvalme, obstipasjon, diaré og fekal inkontinens (11), som alle relateres til underliggende ryggmargsskaderelatert reguleringssvakhet i tarmfunksjonen.

\section{Kolorektal normalfysiologi}

Normal kolorektal funksjon ivaretar absorpsjon av vann og salter, fettsyrenedbryting, transport, lagring og tømming av tarminnhold. Motilitet, transport og defekasjon reguleres av et komplekst samspill mellom ulike autonome nevrogene komponenter, der bare

\section{Hovedbudskap}

- Det er økende kunnskap om ryggmargsskaderelatert reguleringssvakhet av tarmfunksjon

- De patofysiologiske mekanismene er fortsatt utilstrekkelig kartlagt og avspeiles i mangelfulle og lite effektive behandlingstilbud

- Transanal irrigasjon er et verdifullt og veldokumentert behandlingsalternativ og bør prøves ut før stomikirurgiske tiltak

- Standardisert evaluering av ryggmargsskaderelatert funksjonstap gir mulighet til systematisk innsamling. evaluering og sammenlikning av data 
Tabell 1 Forandringer i anorektal- og bekkenbunnsfysiologi hos pasienter med lav ryggmargsskade (conus eller cauda equina) (venstre) og suprakonale skader (høyre). Oversatt og gjengitt med tillatelse fra Elsevier (8)

$$
\text { Konal/kaudal skade }
$$

Forlenget kolorektal transittid

Rektal kontraktilitet

Rektal tonus

Anorektal sensibilitet

Viljestyrt anal sfinkterkontraksjon

Immobilitet viljestyrt. Det finnes et spinalt reflekssenter som gjennom autonom innervasjon bidrar til å opprettholde rektalt samsvar under tarmfylling og som samtidig bidrar til nødvendig peristaltisk aktivitet for defekasjon (12).

\section{Patofysiologi i mage og tarm}

Ryggmargsskaderelaterte forstyrrelser av mage-tarm-funksjon har dels direkte nevrologiske årsaker og dels indirekte årsaker som immobilisering, livsstilsfaktorer og medikamentbruk (13). Den akutte fasen preges av forsinket passasje i hele gastrointestinalkanalen, mens det kroniske forløpet preges av motilitetsforstyrrelser i de nederste tarmavsnittene $(13,14)$.

\section{Nevroanatomisk klassifisering}

Tradisjonelt klassifiseres motornevronskader i ryggmargen som øvre (supranukleære, suprakonale) eller nedre (infranukleære, konale, kaudale). Denne forenklede klassifiseringen vil kunne øke den kliniske forståelsen og gi et nevroanatomisk grunnlag for å klassifisere ryggmargsskaderelatert tarmog bekkenbunnsdysfunksjon som suprakonal eller konal/kaudal slik (1):

- Ved suprakonale skader vil den manglende spinale hemmende kontrollen gi overaktiv, hyperreflektiv venstre colon og rec-
Anale sfinkterspasmer

den eksterne anale sfinktermuskulaturen er tum, og sannsynligvis også forsterket hemmende rektoanal refleksaktivitet. Dette er mekanismer som vil kunne utnyttes i behandlingsmessig sammenheng (digital stimulering, suppositorier, miniklyster) (8).

- Ved skader på conus eller cauda equina vil refleksbuen fra venstre avsnitt av colon/ rectum og analkanalen til sakrale avsnitt $\mathrm{i}$ ryggmargen være brutt. Dette fører til hypoton og hyporefleksiv nedre colon og rectum. I tillegg vil den hemmende rektoanale refleksen være hemmet (8). De kliniske konsekvensene er problematisk rektal evakuering, med distendert rectum og fekal inkontinens $(10,15,16)$.

Krogh og medarbeidere har vist at gastrointestinal og kolorektal transport ved ryggmargsskader er forsinket i akutt fase (innenfor tre uker etter skade) både suprakonalt og konalt (17). En nylig oppfølgingsstudie viste at gastrointestinal og kolorektal transporttid forble forsinket i ett, 13, 19 og 30 år etter ryggmargsskade (18). Den samme gruppen har også gjort studier som viste forskjeller i transittid i ulike kolorektale segmenter. Transittiden i colon transversum og colon descendens var signifikant økt ved suprakonale skader, mens transittid over rektosigmoidavsnittet ikke var økt. Skader på conusnivå medførte signifikant lengre transittid

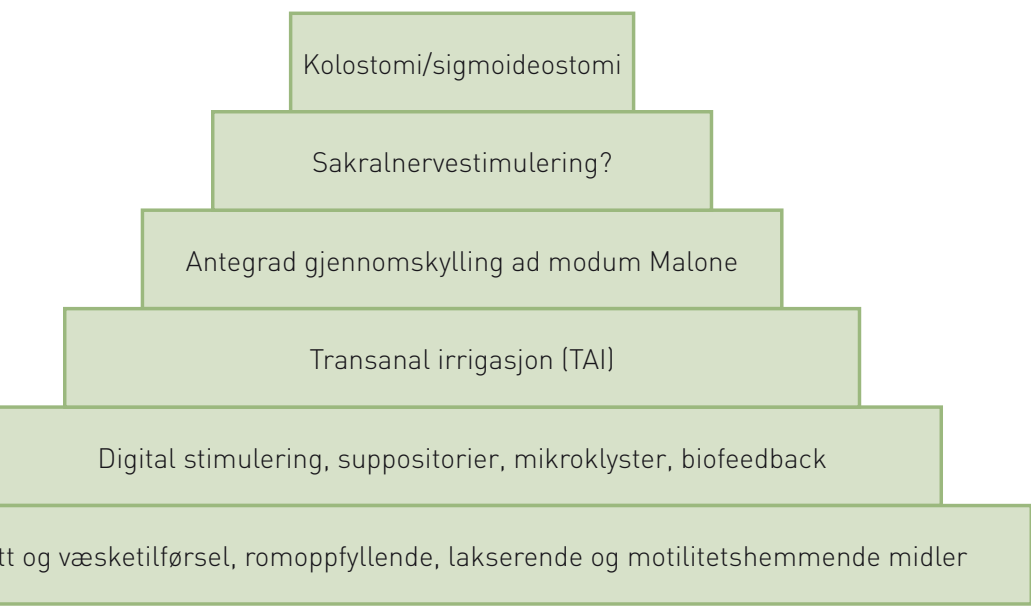

Figur 1 Trinnvis tilnærming ved behandling av nevrogent tap av tarmfunksjon. Oversatt og gjengitt med tillatelse fra Elsevier (8) både $\mathrm{i}$ colon transversum, colon descendens og i rektosigmoidavsnittet (9).

\section{Anal reguleringssvakhet}

Det er gjort undersøkelser på tonus og trykkforhold i analsfinkter og analkanal, med noe motstridende resultater. Krogh og medarbeidere fant følgende årsaker til fekal inkontinens hos ryggmargsskadede pasienter (8):

- manglende viljestyrt kontroll av ekstern analsfinkter

- rektal hyperreaktivitet (ved suprakonale lesjoner)

- redusert rektal tonus og kontraktilitet som forårsaker fekal forstoppelse og distendert rectum (ved konale lesjoner og cauda equina-lesjoner)

- redusert eller tapt anal sensibilitet

Tabell 1 er en sammenstilling av anorektal fysiologi og bekkenbunnsfysiologi ved skader i conus, cauda equina og supraconus.

\section{Kliniske konsekvenser}

Glickman \& Kamms studie viste at $95 \%$ av ryggmargsskadede brukte minst én behandlingsmetode for å igangsette tarmtømming (11). Halvparten måtte ha hjelp av andre. $49 \%$ brukte over 30 minutter til sine tømmingsprosedyrer. Tarmfunksjonen var en kilde til stress hos $54 \%$ og var signifikant assosiert med tidsbruk og inkontinens. Det ble også rapportert høysignifikant sammenheng mellom tidsforbruk på toalettet og skår på Hospital Anxiety and Depression Scale (HADS) (11). Tap av tarmfunksjon ble opplevd tilnærmet like belastende som tap av gangfunksjon.

\section{Klinisk vurdering og utredning}

Sammen med pasientens egenvurdering av symptomenes alvorlighetsgrad vil anamnese som belyser tarmfunksjon både før og etter ryggmargsskaden, være hovedgrunnlaget for valg av behandling. Krogh og medarbeidere har gjennom et multisentersamarbeid utviklet et validert ryggmargsskadespesifikt symptombasert skåringssystem, the Neurogenic Bowel Dysfunction Score (NBD) (19, 20). Det foreligger også en internasjonal konsensus om bruk av definerte kliniske kjernedatasett for klinisk evaluering og forskning $(21,22)$. Disse ble helt nylig validert (23). Digital anorektal undersøkelse gir informasjon om anal muskeltonus, kontraksjon, sensibilitet, anorektal fylning og viljestyrt anal kontraksjon. Ytterligere anorektal fysiologisk testing (kraftmåling med og uten vibrasjon sammenholdt med kliniske funn) gjøres ikke rutinemessig. Ved vår avdeling gjøres det nå pilotundersøkelser for å validere en nyutviklet analprobe til slik bruk.

Et enkelt frontalt abdominalt oversiktsrøntgenbilde vil kunne gi en viss informasjon om grad og utbredelse av fekal stagnasjon samt innhold av luft. Røntgen av transittid er også et alternativ for å oppnå en mer pålitelig vurdering av obstipasjon (17). Hos ryggmargsskadede bør det være lav terskel 


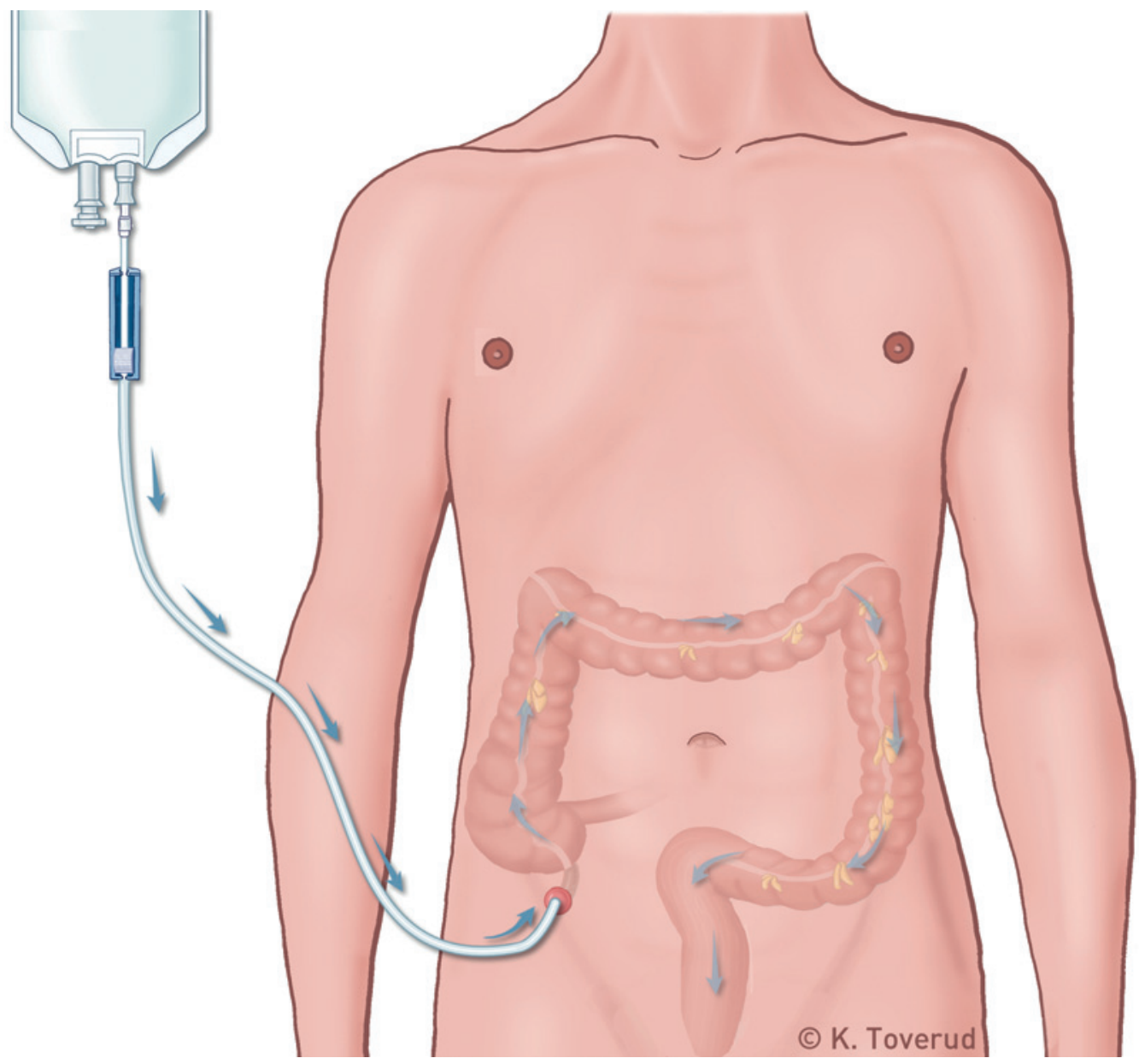

Figur 2 Malones blindtarmstomi for antegrad irrigasjon. Omarbeidet med tillatelse fra Elsevier $(8,30)$

for bildediagnostikk og annen utredning, da pasientene kan ha få symptomer og tegn selv under pågående alvorlige mage-tarm-relaterte tilstander. Et eksempel er en pasient som ved røntgen thorax på annen indikasjon tilfeldig fikk påvist fri luft $\mathrm{i}$ buken på grunn av asymptomatisk colonperforasjon.

\section{Behandling}

Obstipasjon og fekal inkontinens er et av hovedproblemene for de ryggmargsskadede. Pasientene rangerer ønsket om kontroll på blære og tarmfunksjon høyt (7). Vår erfaring er at andre ryggmargsskaderelaterte funksjonstap forsterker det nevrogent betingede tarmfunksjonstapet. Dette fordi redusert mobilitet og mangelfull hånd- og fingerfunksjon vil kreve hjelpemiddelteknisk tilrettelegging og av og til personlig hjelp til å gjennomføre tarmtømmingsprosedyrer.

\section{Grunnleggende konservativ behandling}

Clinical practice guidelines fra 1998 er en omfattende samling av anbefalinger og forslag til utredning og behandling av nevrogene tarmfunksjontap hos voksne med ryggmargsskader (24). Retningslinjene er grundige, systematiske og til hjelp for etablering av tarmtømmingsprosedyrer. Før medikamentelle behandlingstiltak vurderes bør man lage en plan for regelmessige tømmingsprosedyrer, der alle tilgjengelige livsstilsrelaterte alternativer prøves ut. Det vitenskapelige kunnskapsgrunnlaget for slike konservative behandlingstiltak er imidlertid fortsatt mangelfult (25). I en Cochrane-oversikt fant man at antallet studier av behandlingstiltak var lite og av dårlig kvalitet (26). Likevel synes grunnleggende konservative tiltak å bidra til akseptable tarmtømmingsprosedyrer for mange med ryggmargsskader (9).

Bruk av lakserende eller obstiperende medikamenter er en del av den konservative behandlingen og bør etter vår erfaring prøves ut før man vurderer ytterligere behandlingstiltak. Manuell digital stimulering eller evakuering av anorectum brukes også av mange (8). I tillegg vil rektal stimulering med suppositorier og/eller miniklyster kunne forsterke effekten av digital stimulering, mens biofeedbackbehandling ikke har gitt påvisbar tilleggseffekt hos personer med ryggmargsskader (25). Bruk av selvekspanderende anale tamponger er et alternativ ved inkontinens av feces eller flatus (25).

Krogh og medarbeidere har publisert en artikkel med forslag til trinnvis behandling av nevrogen reguleringssvakhet av tarmfunksjonen, gjeldende for flere nevrologiske tilstander (8). Vi mener at artikkelen gir en god oversikt over de tilgjengelige behandlingsalternativene (fig 1).
De første to trinnene i «behandlingstrappen» dreier seg om basale konservative metoder (fig 1). Trinn 3 er transanal irrigasjon (TAI) eller transanal retrograd irrigasjon (TRI). Dette er en skånsom prosedyre som effektivt tømmer rectum, ofte også venstre colonavsnitt, ved hjelp av et kommersielt utviklet teknisk produkt. Prosedyren er vist å ha gunstig innflytelse på obstipasjon og fekal inkontinens og gir forbedret symptomrelatert livskvalitet $(19,27)$. Metoden er dessuten kostnadseffektiv sammenliknet med konservative behandlingstiltak (28). En nyere studie viste at effekten av transanal irrigasjon avtar over tid, og forbedret seleksjon av aktuelle brukere av denne metoden er viktig (29). Trinn 4 er antegrad gjennomskylling ad modum Malone (Malone Antegrade Colonic Enema, MACE) (fig 2) (30). Ved denne kirurgiske løsningen anlegges det en blindtarmstomi (appendikostomi) som tilgang til proksimale del av colon. Blindtarmstomien muliggjør antegrad gjennomskylling av rektocolon, vanligvis med springvann. Flere studier har vist at man slik oppnår effektiv tømming av tykktarmen hos personer med spina bifida og hos voksne med nevrogent tarmfunksjonstap $(31,32)$. Furlan og medarbeidere viste $\mathrm{i}$ en oppfølgningsstudie over tre år at antegrad gjennomskylling ga bedre resultat 
enn andre kirurgiske behandlingsmetoder (33). Sakral nervestimulering av de fremre efferente røtter i S2- og S3-nivå vil kunne være et femte behandlingstrinn og gi effekt på behandlingsresistent fekal inkontinens og obstipasjon (34).

Anleggelse av kolostomi/ileostomi kan ses på som en nødløsning når andre behandlingsalternativer mislykkes. Stomikirurgiske behandlingsmetoder gir imidlertid økt grad av selvstendighet, redusert tidsbruk til tømmingsprosedyrer, økt livskvalitet og økt pasienttilfredshet. Mange pasienter angir at de gjerne skulle ha gjennomført stomikirurgisk behandling på et tidligere tidspunkt $(35-38)$. Ved St. Olavs hospital har vi siden 1999 i samarbeid med rehabiliteringslege og gastrokirurg gjennomført over 60 stomikirurgiske inngrep på ryggmargskadede pasienter (upubliserte data fra egen avdeling). Vår avdeling gjør pre- og postoperativ oppfølging og vi har utdannet egen stomiterapeut.

Indikasjonsstillingen for stomi er $\mathrm{i}$ all hovedsak basert på empiri og i liten grad på kunnskapsbasert viten. Effekten av ulike stomiløsninger er $\mathrm{i}$ vår populasjon fortsatt usikker både med tanke på livskvalitet og tidlige og sene komplikasjoner. På denne bakgrunn gjør vi nå en protokollbasert systematisk gjennomgang av kliniske data sammenholdt med selvrapporterte opplysninger.

\section{Erik Kr. Sigurdsen (f. 1944)}

er spesialist i fysikalsk medisin og rehabilitering. Han er tidligere overlege ved Avdeling for ryggmargsskader, St. Olavs hospital, nå helsefaglig rådgiver ved samme avdeling.

Forfatter har fylt ut ICMJE-skjemaet og oppgir ingen interessekonflikter.

\section{Tom Tørhaug (f. 1969)}

er lege i spesialisering i fysikalsk medisin og rehabilitering. Han jobber nå i kombinert stilling som konstituert overlege ved Avdeling for ryggmargsskader, St. Olavs hospital og ph.d.kandidat ved Institutt for nevromedisin, NTNU. I seks år har han hatt styreverv i Norsk forening for fysikalsk medisin og rehabilitering.

Forfatter har fylt ut ICMJE-skjemaet og oppgir ingen interessekonflikter.

\section{Litteratur}

1. Alexander MS, Biering-Sorensen F, Bodner D et al. International standards to document remaining autonomic function after spinal cord injury. Spinal Cord 2009; 47: 36-43.

2. American Spinal Injury Association. Reference manual for the International Standards for Neurological Classification of Spinal Cord Injury. Chicago, IL: American Spinal Injury Association, 2003.

3. Marino RJ, Barros T, Biering-Sorensen F et al. International standards for neurological classification of spinal cord injury. J Spinal Cord Med 2003: 26 (suppl 1): S50-6.

4. Chiu WT, Lin HC, Lam C et al. Review paper: epidemiology of traumatic spinal cord injury: com parisons between developed and developing countries. Asia Pac J Public Health 2010: 22: 9-18.

5. Lin VW, Cardenas DD. Spinal cord medicine. Principles and practice. New York, NY: Demos, 2003.

6. Hagen EM, Eide GE, Rekand T et al. A 50-year follow-up of the incidence of traumatic spinal cord injuries in Western Norway. Spinal Cord 2010; 48 $313-8$

7. Anderson KD. Targeting recovery: priorities of the spinal cord-injured population. J Neurotrauma 2004: 21: 1371-83.

8. Krogh K, Christensen P. Neurogenic colorectal and pelvic floor dysfunction. Best Pract Res Clin Gastroenterol 2009; 23: 531-43.

9. Krogh K, Nielsen J, Djurhuus JC et al. Colorectal function in patients with spinal cord lesions. Dis Colon Rectum 1997; 40: 1233-9.

10. Lynch AC, Wong C, Anthony A et al. Bowel dysfunc tion following spinal cord injury: a description of bowel function in a spinal cord-injured population and comparison with age and gender matched controls. Spinal Cord 2000; 38: 717-23.

11. Glickman S, Kamm MA. Bowel dysfunction in spinalcord-injury patients. Lancet 1996; 347: 1651-3.

12. Brading AF, Ramalingam T. Mechanisms controlling normal defecation and the potential effects of spinal cord injury. Prog Brain Res 2006; 152: $345-58$

13. Holtz ALR. Ryggmärgsskador - behandling och rehabilitering. 1. utg. Stockholm: Studentlitteratur, 2008

14. Enck P, Greving I, Klosterhalfen S et al. Upper and lower gastrointestinal motor and sensory dysfunction after human spinal cord injury. Prog Brain Res 2006: 152: 373-84.

15. Krogh K, Mosdal C, Gregersen H et al. Rectal wall properties in patients with acute and chronic spinal cord lesions. Dis Colon Rectum 2002; 45: $641-9$

16. Krogh K, Olsen N, Christensen P et al. Colorectal transport during defecation in patients with lesions of the sacral spinal cord. Neurogastroenterol Motil 2003; 15: 25-31.

17. Krogh K, Mosdal C, Laurberg S. Gastrointestinal and segmental colonic transit times in patients with acute and chronic spinal cord lesions. Spina Cord 2000; 38: 615-21.

18. Faaborg PM, Christensen P. Rosenkilde $\mathrm{M}$ et al. Do gastrointestinal transit times and colonic dimensions change with time since spinal cord injury? Spinal Cord 2011; 49: 549-53.

19. Christensen P, Bazzocchi G, Coggrave M et al. A randomized, controlled trial of transanal irrigation versus conservative bowel management in spinal cord-injured patients. Gastroenterology 2006; 131: 738-47

20. Krogh K, Christensen P, Sabroe S et al. Neurogenic bowel dysfunction score. Spinal Cord 2006; 44: 625-31.

21. Krogh K, Perkash I, Stiens SA et al. International bowel function basic spinal cord injury data set. Spinal Cord 2009; 47: 230-4.
22. Krogh K, Perkash I, Stiens SA et al. International bowel function extended spinal cord injury data set. Spinal Cord 2009; 47: 235-41.

23. Juul T, Bazzocchi G, Coggrave M et al. Reliability of the international spinal cord injury bowel func tion basic and extended data sets. Spinal Cord 2011; 49: 886-91

24. Spinal Cord Medicine Consortium. Clinical practice guidelines: Neurogenic bowel management in adults with spinal cord injury. J Spinal Cord Med 1998; 21: 248-93.

25. Preziosi G, Emmanuel A. Neurogenic bowel dysfunction: pathophysiology, clinical manifestations and treatment. Expert Rev Gastroenterol Hepatol 2009; 3: 417-23.

26. Coggrave M, Wiesel PH, Norton C. Management of faecal incontinence and constipation in adults with central neurological diseases. Cochrane Database Syst Rev 2006: nr. 2: CD002115.

27. Christensen P, Olsen N, K et al. Scintigraphic assessment of retrograde colonic washout in fecal incontinence and constipation. Dis Colon Rectum 2003; 46: 68-76.

28. Christensen P, Andreasen J, Ehlers L. Cost-effectiveness of transanal irrigation versus conservative bowel management for spinal cord injury patients. Spinal Cord 2009; 47: 138-43.

29. Faaborg PM, Christensen P, Kvitsau B et al. Longterm outcome and safety of transanal colonic irrigation for neurogenic bowel dysfunction. Spinal Cord 2009; 47: 545-9.

30. Malone PS, Ransley PG, Kiely EM. Preliminary report: the antegrade continence enema. Lancet 1990; 336: 1217-8

31. Christensen P, Kvitzau B, Krogh K et al. Neurogenic colorectal dysfunction - use of new antegrade and retrograde colonic wash-out methods. Spinal Cord 2000; 38: 255-61.

32. Worsøe J, Christensen P. Krogh Ket al. Long-term results of antegrade colonic enema in adult patients: assessment of functional results. Dis Colon Rectum 2008: 51: 1523-8.

33. Furlan JC, Urbach DR, Fehlings MG. Optimal treatment for severe neurogenic bowel dysfunc tion after chronic spinal cord injury: a decision analysis. Br J Surg 2007: 94: 1139-50.

34. Mowatt G, Glazener C, Jarrett M. Sacral nerve stimulation for fecal incontinence and constipation in adults: a short version Cochrane review. Neurourol Urodyn 2008; 27: 155-61.

35. Branagan G. Tromans A, Finnis D. Effect of stoma formation on bowel care and quality of life in patients with spinal cord injury. Spinal Cord 2003 41: $680-3$

36. Randell N, Lynch AC, Anthony A et al. Does a colostomy alter quality of life in patients with spinal cord injury? A controlled study. Spinal Cord 2001; 39: 279-82

37. Safadi BY, Rosito O, Nino-Murcia M et al. Which stoma works better for colonic dysmotility in the spinal cord injured patient? Am J Surg 2003; 186 437-42.

38. Stone JM, Wolfe VA, Nino-Murcia M et al. Colostomy as treatment for complications of spinal cord injury. Arch Phys Med Rehabil 1990; 71: 514-8.

Mottatt 1.9. 2010, første revisjon innsendt 31.5. 2011, godkjent 27.10. 2011. Medisinsk redaktør Are Brean. 